\title{
Relato de Experiência: Abordagem da multiplicidade cultural na formação do povo brasileiro em aula de geografia no Colégio Estadual Yvone Pimentel
}

\author{
Informe de Experiencia: Enfoque de la diversidad cultural en la formación \\ del pueblo brasileño en clase de geografía en el State College Yvone \\ Pimentel
}

\section{Experience report: Approach on cultural multiplicity on Brazilian people formation in a Colégio Estadual Yvone Pimental Geography class.}

\section{Poliana Back da Silveira' Thays Ukan ${ }^{2}$}

\begin{abstract}
Resumo
Frente ao processo de retrocesso histórico que vem ocorrendo no sistema educacional brasileiro há tempos, e que recentemente teve seu ápice com a aprovação da Medida Provisória 746/2016 referente à Reforma no Ensino Médio, entende-se que atualmente a escola precisa buscar alternativas à onda tecnicista que invade a educação brasileira, instigando professores a trazer novas práticas que abordem a importância da consciência crítica-cidadã bem como a sensibilidade e criatividade dos alunos. Nesse contexto, o presente trabalho apresenta o relato de experiência de uma aluna bolsista no Programa Institucional de Bolsas a Iniciação à Docência - PIBID, que em conjunto com uma segunda aluna bolsista no Programa Institucional de Bolsas para Iniciação Científica - PIBIC, desenvolveu uma dinâmica para alunos do sétimo ano do Ensino Fundamental no Colégio Estadual Yvone Pimentel, em Curitiba - PR. A dinâmica possui como objetivo abordar a multiplicidade étnica e cultural na formação do povo brasileiro, buscando combater preconceitos e trazer pra sala de aula o conceito de identidade, fomentando debate e reflexão entre os estudantes. A dinâmica foi realizada em abril de 2017 no setor público de educação.
\end{abstract}

Palavras-chave: Educação, Dinâmica, Multiplicidade Étnico-Cultural, Povo Brasileiro.

\section{Resumen}

Frente al histórico proceso de reversión que ha tenido lugar en el sistema educativo brasileño desde hace algún tiempo, y recientemente alcanzó su punto máximo con la aprobación de la Medida Provisional 746/2016 en relación con la reforma de la escuela secundaria, se entiende que en la actualidad la escuela tiene que buscar alternativas a la ola tecnicismos que invade la educación brasileña, lo que provocó maestros para traer nuevas prácticas que abordan la importancia de la conciencia ciudadana crítica y la sensibilidad y la creatividad de los estudiantes. En este contexto, este documento presenta el informe de la experiencia de una compañera de estudios en el Programa de Becas Institucionales de Introducción a la Enseñanza - PIBID, lo que unido a una segunda beca de estudios en el Programa de Becas Institucionales de Iniciación Científica - PIBIC desarrolló un impulso para los estudiantes del séptimo grado de la escuela primaria en State College Yvone Pimentel, en Curitiba - PR. La dinámica tiene como objetivo acercarse a la diversidad étnica y cultural en la formación del pueblo brasileño, que busca combatir los prejuicios y aportan a la clase el concepto de identidad, fomentando el

\footnotetext{
${ }^{1}$ Graduanda em Licenciatura e Bacharelado em Geografia; Universidade Federal do Paraná - UFPR; Curitiba, Paraná, Brasil; polianaback@gmail.com

2 Graduada em Bacharelado em Artes Visuais; Universidade Federal do Paraná - UFPR; Graduanda em Licenciatura e Bacharelado em Geografia; Universidade Federal do Paraná - UFPR; Curitiba, Paraná, Brasil; thaysukan@gmail.com.
}

Trabalho apresentado no I Seminário Latino-Americano de Estudos em Cultura - SEMLACult, Foz do Iguaçu/PR, Brasil, 2017. 
debate y la reflexión entre los estudiantes. La dinámica se llevó a cabo en abril de 2017 la educación del sector público.

Palabras clave: Educación, Dinámica, Multiplicidad Étnica y Cultural, Pueblo Brasileño.

\section{Abstract}

Brazilian educational system has suffered a backslide over the last few decades, reaching its peak with the approval of Provisional Measure 746/2016, the secondary school reform. Hance, it is understood that the schools are in need of alternatives to the technicality trend that has been growing inside it, such as to bring inside classroom practices that address the importance of critical civic awareness and the student's sensitiveness. In this context, this paper presents an experience report conducted by two undergraduate researchers, about the implementation of a dynamics in a 7th grade classroom of Yvone Pimental school, in Curitiba, PR, in April 2017. This dynamics approaches the ethnical-cultural multiplicity in Brazilian people formation, aiming to fight prejudice and bring the concept of identity to the classroom, instigating debate and reflection among the students.

Keywords: Education, Dynamics, Ethnical-Cultural Multiplicity, Brazilian People.

\section{Introdução}

A Prática de Ensino no Brasil teve seu desenvolvimento atrelado a implementação da Lei de Primeiras Letras, de 1827 e à instauração da República, em 1889 (GUEDES, SCHELBAUER, 2010, p.228). Foi somente a partir deste período que a formação docente brasileira passou a ter em seu curriculo a integração e a discussão, mesmo que incipiente, de atividades que desenvolvessem a prática dos professores em sala de aula. Por sua vez, o ensino de Geografia, que nos anos recentes tem passado por situações conturbadas, tornou-se matéria escolar obrigatória no ano de 1831, sendo seu ingresso institucional relacionado a obrigatoriedade da disciplina em concursos de Direito (MELO, VLACH, SAMPAIO, p. 2683). Com o tempo, a disciplina ganhou maior espaço e flexibilidade dentro do sistema de ensino e atualmente pode compreender uma série de conceitos importantes para a formação cidadã e humana de crianças e adolescentes em idade escolar. Por ter tido seu caráter tecnicista diminuido diante de novos conceitos, a disciplina de Geografia, junto com outras, vem perdendo seu espaço nas escolas brasileiras. Porcher (1973) ao comentar o ensino de arte, aponta para o mesmo problema: o menosprezo à disciplinas que não têm caráter técnico e imediato, o que as relaciona ao ócio, criando uma barreira quase intransponível nos ambientes escolares, fazendo com que suas cargas horárias sejam diminuidas, ou, como no caso da Medida Provisória do Novo Ensino Médio, a MPV 746/2016 aprovada sobre a forma de projeto de lei de Conversão (PLV) 34/2016, sejam excluídas, o que apresenta um enorme retrocesso histórico a educação pública no Brasil (AGB, 2017). Optar por um sistema de ensino que preze pelo conhecimento técnico e exclua outras maneiras de aprendizado, tem como característica uma certa limitação que, inclusive, repercute sobre os estudantes, pois, faz crer, que estes são desprovidos de conhecimento anterior, estando ali como sujeitos vazios 
que serão preenchidos com conteúdo formal. Paulo Freire comenta que desde o princípio da experiência formadora é importante assumir o aluno como produtor de saber, onde o professor não é mero transmissor de conhecimento, mas alguém que cria possibilidades para sua produção e construção (FREIRE, 1996, p. 22). Um ambiente escolar que leve em consideração as identidades dos alunos e sua diversidade, compreendendo que o conhecimento formal técnico por si só não dá a real dimensão do mundo à jovens e crianças, diminuindo o papel da escola no desenvolvimento cidadão, é fundamental.

A prática que será aqui relatada, dá conta de trazer um ensino de Geografia onde os alunos têm autonomia, discutindo questões culturais e identitárias. Neste contexto, entendeuse a identidade como um processo marcado pela diferença, ou seja, ela é relacional e adquirida por meio da linguagem e de sistemas simbólicos (WOODWARD, 2000, p. 08). Na atividade desenvolvida, ainda, utilizou-se o apelo a antecedentes históricos, o que, para Woodward, não se limita somente a um sistema simbólico, mas também social. Para a autora, ao se discutir identidade, começa-se também uma discussão sobre o que ela chama de "circuito da cultura". Isto é, um sistema de representações produzidos, compreendido como processo que estabelece identidades individuais e coletivas onde a cultura molda a identidade ao dar sentido a experiência (WOODWARD, 2000, p. 19). Por fim, o relato terá como princípio a autonomia dos alunos nos processo de ensino aprendizagem em uma aula de Geografia de escola estadual, e discussões acerca dos processos culturais e identitários pelos quais estes alunos passam em suas vivências, atentando para o fato de que a atividade foi realizada em uma escola formal da rede pública do estado do Paraná, o que cria limitações metodológicas.

\section{Contextualização}

Dentro das universidades brasileiras existem diversos projetos extracurriculares que buscam complementar a formação dos universitários, proporcionando experiências diferenciadas que ampliam o processo de ensino e aprendizagem. Entre estes projetos, existe o Programa Institucional de Bolsas para Iniciação Científica - PIBIC, que visa incentivar a produção científica no Brasil ofertando bolsas para os estudantes que desejam realizar pesquisas dentro da universidade. Ambas as autoras fazem parte do PIBIC no Laboratório de Território, Cultura e Representações - LATECRE, que se volta à estudos em Geografia Cultural dentro Departamento de Geografia da Universidade Federal do Paraná (UFPR). Além deste, outro projeto extracurricular fez parte do processo que gerou este relato de 
experiência, sendo uma das participantes do programa de Iniciação Científica, também participante do Programa Institucional de Bolsas para Iniciação à Docência - PIBID, que foi criado com o objetivo de aperfeiçoar a formação de professores nos cursos de licenciatura ofertados nas instituições de ensino superior no Brasil, gerando uma parceria entre as universidades e a rede pública de ensino básico. Os alunos participantes do projeto recebem bolsas para acompanhar os professores de escolas estaduais uma vez por semana, onde auxiliam nas atividades gerais, desenvolvem práticas de ensino diferenciadas baseadas no conteúdo trabalhado no colégio e as aplicam no decorrer do ano letivo. Uma das autoras, bolsista no PIBID - Geografia 1, vem desenvolvendo projetos com os sétimos anos do Ensino Fundamental no Colégio Estadual Yvone Pimentel, localizado no bairro Novo Mundo, em Curitiba - PR.

O Plano de Diretrizes Curriculares da Educação Básica no Ensino de Geografia, estabelecido pela Secretaria de Educação do Governo do Estado do Paraná em 2008, divide os fundamentos para a organização e abordagem dos conteúdos específicos que o professor deverá trabalhar no Ensino Fundamental e Médio em quatro Conteúdos Estruturantes. O Conteúdo Estruturante n.4, intitulado “A Dimensão Cultural e Demográfica do Espaço Geográfico", expressa em duas páginas a importância da abordagem de questões culturais durante o ensino da disciplina de Geografia na educação básica, bem como a base teórica para tal. Segundo o Plano de Diretrizes:

(...) os estudos sobre os aspectos culturais e demográficos do espaço geográfico contribuem para a compreensão desse momento de intensa circulação de informações, mercadorias, dinheiro, pessoas e modos de vida. (...) Por isso, mais do que estudar particularidades, este conteúdo estruturante preocupa-se com os estudos da constituição demográfica das diferentes sociedades; as migrações que imprimem novas marcas nos territórios e produzem novas territorialidades, e com as relações político-econômicas que influenciam essa dinâmica.(PLANO DE DIRETRIZES CURRICULARES DA EDUCAÇÃO BÁSICA NO ENSINO DE GEOGRAFIA, 2008)

Pode-se notar que no Plano de Diretrizes os estudos de Geografia da População e Geografia Cultural são unidos em um mesmo Conteúdo Estruturante e como a orientação deste da maior evidência aos conteúdos da primeira área citada. Em sala de aula, os livros didáticos tendem a dar maior ênfase à estudos populacionais que abordam questões migratórias e pirâmides etárias do que às questões culturais, contudo, no setor público de ensino o professor tem certa liberdade didática, ou seja, pode abordar os conteúdos levando em consideração as particularidades do grupo de alunos com o qual trabalha afim de deixar 
estes conteúdos mais interessantes, contanto que não deixe nenhum dos assuntos obrigatórios de fora.

$\mathrm{Na}$ experiência vivenciada por uma das autoras, enquanto bolsista no PIBID, a professora orientadora do projeto que leciona a disciplina de geografia no C.E. Yvone Pimentel, porpôs que a aluna desenvolvesse uma dinâmica abordando questões culturais, unindo sua prática do PIBIC, na área da Geografia Cultural, à do PIBID. Neste contexto deuse o processo que gerou a dinâmica, em que as autoras buscaram criar um método alternativo de ensino, sabendo da carência de práticas diferenciadas na rede pública escolar brasileira, além da falta de aprofundamento em conteúdos especificamente culturais dentro do ensino de geografia no estado. Ambas as autoras desenvolveram a atividade juntas, usando como base conhecimentos adquiridos ao longo da pesquisa na área de Geografia Cultural no PIBIC, entretanto apenas a bolsista do PIBID aplicou a atividade.

\subsection{A Experiência}

A experiência relatada foi realizada no dia 17/04/2017 com quatro turmas diferentes dos 7os anos do Ensino Fundamental do Colégio Estadual Yvone Pimentel, sendo elas 7oB, $7 \mathrm{oC}, 7 \mathrm{oD}$ e $7 \mathrm{oE}$. As turmas eram formadas por aproximadamente 30 alunos, e a atividade foi desenvolvida durante 1 (uma) aula de 50 (cinquenta) minutos com cada uma das turmas. A atividade foi dividida em três partes onde a primeira parte foi composta por exposição de conceitos e debate entre os alunos, a segunda, composta pela realização da dinâmica, e a terceira foi quando relacionou-se os conceitos expostos com a prática realizada.

A oportunidade para a realização da atividade ocorreu quando a professora orientadora deu início ao conteúdo que aborda a formação do povo brasileiro, com as turmas dos sétimos anos. O conteúdo foi trabalhado pela professora partindo do pressuposto de que o povo brasileiro tem sua formação composta por quatro principais grupos étnicos: portugueses, africanos, indígenas e imigrantes europeus (alemães, italianos, poloneses, ucranianos, entre outros). Este conceito foi extraído do livro didático de geografia adotado por ela, da coleção "Para Viver Juntos" da Editora SM, 4a edição de 2015. Partindo dessa noção, a experiência começou com a bolsista escrevendo no quadro negro a palavra "miscigenação". Grande parte dos alunos em todas as turmas nas quais a atividade foi aplicada, não conheciam a palavra. Sendo assim, a bolsista reservou parte da dinâmica para pensar com os alunos o significado de miscigenação, expondo sua importância no decorrer da formação do povo brasileiro, onde esta entra como peça chave no processo de colonização, entendendo, ainda, colonização como 
um processo de subordinação, dominação e exploração efetuado for nações em amplos territórios ao longo da história, sob o argumento da superioridade étnico-racial (ENCICLOPÉDIA ESPASA, 2017). Para Levi-Strauss “a atitude mais antiga e que repousa, sem dúvida, sobre fundamentos psicológicos sólidos, [...] consiste em repudiar pura e simplesmente as formas culturais, morais, religiosas, sociais e estéticas mais afastadas daquelas com que nos identificamos" (p. 4). Os outros são "selvagens", comenta Levi-Strauss e, essa perspectiva argumentativa legitíma não somente a colonização de territórios físicos, mas também simbólicos, o que pode ser analisado nos alunos, ao longo da dinâmica.

Outras ideias introduzidas foram as de identidade e ancestralidade, que levaram os alunos a indagarem sua descendência dentro dos quatro principais grupos formadores do povo brasileiro, de acordo com o que haviam aprendido em aula. Vários se confundiram ao tentar uma autodefinição, pois descendiam de vários grupos simultaneamente. Neste caso, a bolsista apontou essa situação como uma prova de como o povo brasileiro é, verdadeiramente, miscigenado: não há descendência de apenas um grupo étnico, mas a mistura de vários, e é isso o que forma os brasileiros. Esses exemplos vivenciados pelos próprios alunos em suas famílias promoveu uma compreensão prática do que realmente é a miscigenação, para além do conceito teórico. Ao longo da primeira parte da dinâmica, pôde-se notar como alguns descendentes de africanos e indígenas não se identificavam como tal, alegando descendência de imigrantes europeus, mesmo quando continham traços físicos que evidenciavam uma descendência majoritária dos povos africanos e indígenas, como a cor da pele, por exemplo. Neste contexto, pode-se perceber os efeitos da colonização na relação de identidade étnica dos alunos, na medida em que descendentes de povos historicamente dominados e diminuídos não se viam como tal.

A partir daí os alunos iniciaram um debate com o objetivo de refletir sobre os impactos desse processo de colonização, que nasceu com uma ideia progressista e imposição étnico-racial ao conceito de identidade de cada um. Em quase todas as turmas foram abordadas as contribuições culturais de cada etnia trabalhada, na formação de uma cultura propriamente brasileira, onde foram citados exemplos relacionados a gastronomia, danças, músicas e festas brasileiras. Vários alunos que não se identificavam como afro-descendentes passaram a fazê-lo no momento em que descobriram que o "hip hop" foi criado majoritariamente por artistas negros, sendo o gênero musical muito popular entre os estudantes. Os debates ajudaram a desconstruir uma série de preconceitos que os alunos tinham, mas não entendiam a origem. Na Fotografia 1, abaixo, pode-se observar como ocorreu o debate em uma das turmas, onde as limitações metológicas impostas pela educação 
escolar pública e formal das escolas brasileiras, ainda cria um ambiente escolar tradicional e hierarquico difícil de ser desmanchado, mas que não chega a impedir a riqueza de ideias e discussões.

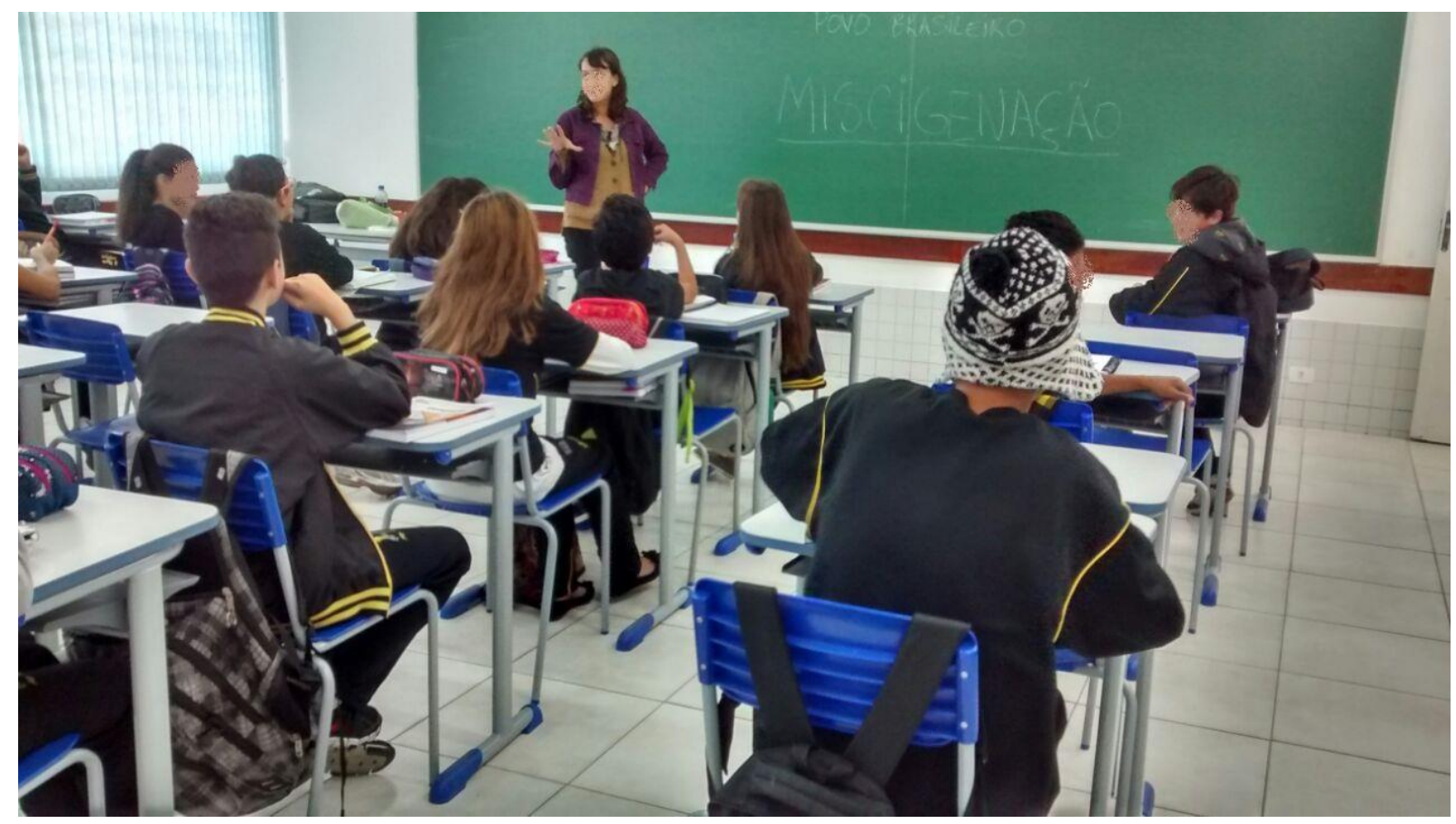

Fotografia 1: Debate em sala de aula

Fonte: Acervo da autora

Após todas as explanações introdutórias terem sido realizadas, a bolsista solicitou que os alunos se dividissem em quatro grupos, sendo cada grupo referente à um grupo étnico formador do povo brasileiro. O parâmetro para a divisão eram traços físicos que predominavam em cada aluno, partindo da noção de que eles se encaixavam em todos os grupos étnicos, pois, possivelmente, eram descendentes dos quatro grupos por conta da miscigenação. Depois da divisão ser concluída, a turma foi para o pátio da escola onde cada grupo ficou enfileirado de frente para o outro, formando um quadrado com quatro filas, como pode ser observado em partes, na Fotografia 2. Desta maneira, havia uma divisão espacializada entre cada grupo baseada nas diferenças físicas dos aluno, que, por sua vez, estavam relacionadas com um dos grupos étnicos estudados na disciplina de geografia. 


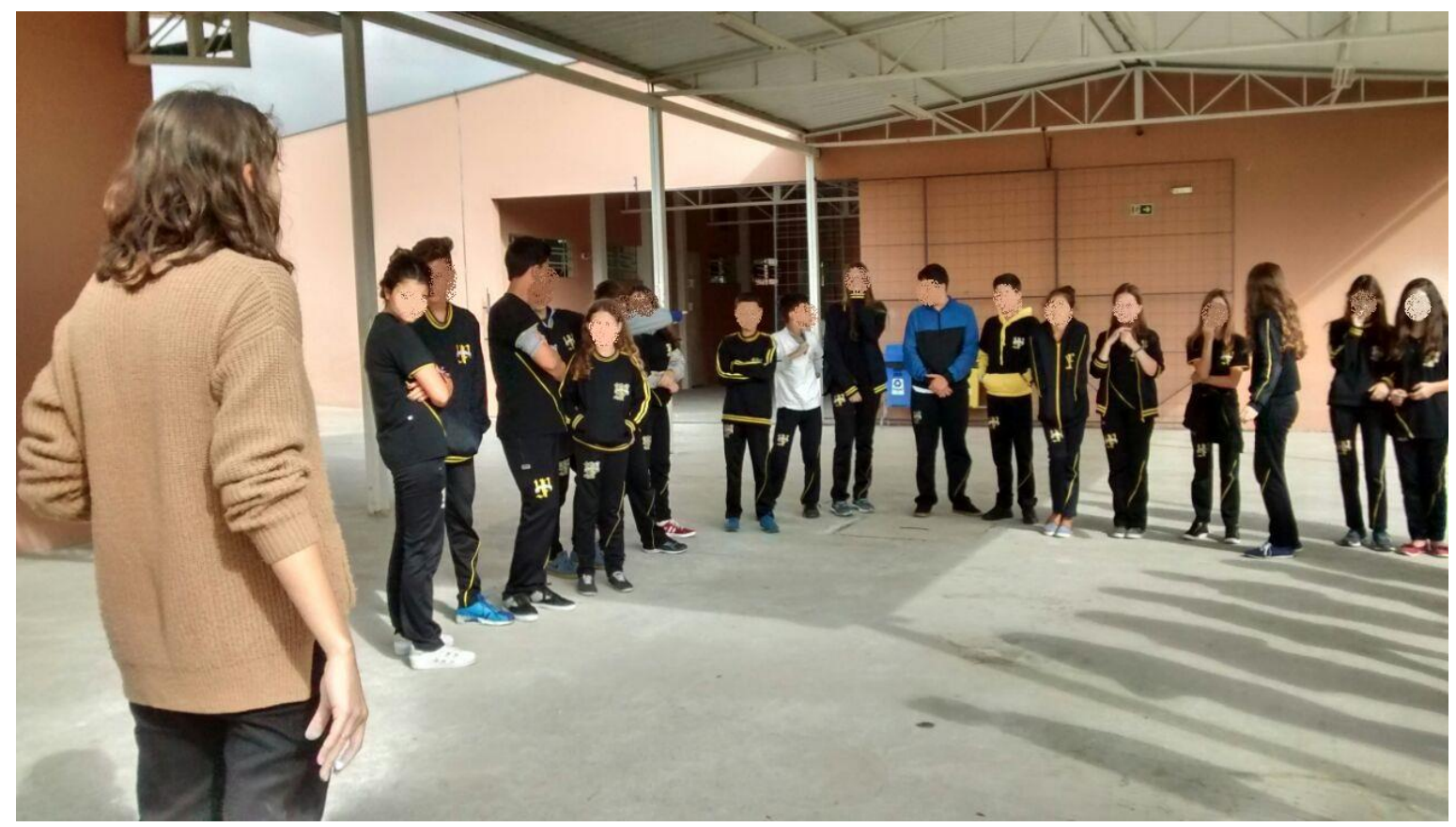

Fotografia 2: Início da dinâmica

Fonte: Acervo da autora

A dinâmica se desenrola a partir desse momento, quando a bolsista pára em um canto do pátio em que não haviam alunos, e de lá passa a dizer para que todos que gostassem de jogar futebol se concentrassem naquele canto, junto com ela. Diversos alunos, de diferentes filas, se reuniram onde a bolsista estava. Em seguida a bolsista se dirigiu a outro canto vazio, e de lá pediu para que todos os estudantes que gostassem de comer pizza, concentrassem-se naquele local específico. A grande maioria dos alunos acumularam-se lá. Assim, a bolsista foi abordando pontos aleatórios de possíveis convergências entre os alunos, a partir dos quais eles deveriam se reunir em locais específicos no pátio: os alunos que tocavam algum instrumento musical, os que tinham rinite alérgica, os que gostavam de estudar no C.E. Yvone Pimentel, os que gostavam de ir ao cinema nos fins de semana, os que ouviam "hip hip", os que ouviam "funk" e os que ouviam "rock", e assim sucessivamente. Depois de passados cerca de 15 minutos, todos retornaram à sala de aula onde começaram a expressar o que haviam aprendido com aquilo. Essa parte da atividade foi liderada pelos alunos, com poucas contribuições da bolsista. Os estudantes passaram a relacionar tudo que haviam refletido no debate anteriormente com a dinâmica de maneira orgânica e livre.

\section{Resultados e Conclusões}

A experiência que se desdobrou neste relato teve como objetivo trazer reflexões sobre o ensino no Brasil, mais especificamente, sobre o ensino de Geografia, levando em 
consideração sua importância e obrigatoriedade. A Geografia, como disciplina e ciência, traz uma série de possibilidades de conteúdos que podem ser trabalhos em sala de aula, tanto dentro de uma perspectiva técnica, referente ao manuseio de mapas e sua elaboração, bem como conhecimento acerca da paisagem, mas, ainda, levantando questões críticas, onde há a importância de um olhar analítico. Todas as abordagens, em conjunto, trazem a possibilidade de uma formação humana e cidadã aos alunos de ensino fundamental e médio no Brasil. $\mathrm{O}$ referente trabalho demonstra que a auto identificação, a retomada de consciência, a autonomia e o debate realizado pelos alunos do C.E. Yvone Pimentel, são todos resultados de uma atividade que traz uma dinâmica que faz com que os alunos compreendam a constituição do povo brasileiro, com todas as suas diferenças, trazendo, como o principal resultado, o combate a intolerância que, muitas vezes, nasce incoscientemente nos alunos.

Como relatado ao longo do trabalho, questões referentes às identidades foram as mais marcantes. Identidade aqui, foi entendida dentro do conceito desenvolvido pela autora Kathryn Woodward, onde esta é marcada pela diferença e precisa de algo que está fora dela para existir, além de ser tanto simbólica quanto social. No caso das identidades dos alunos do C.E. Yvone Pimentel, esta passou a ser entendida através dos seus antecedentes históricos, entrando em níveis de ancestralidade onde, partindo da ideia de miscigenação, buscou-se trazer aos alunos a consciência de suas identidades étnicas, supostamente perdidas, mas que, devido a miscigenação, compunham uma nova identidade nos alunos, mesmo quando esta não era materialmente vista por eles. O trabalho buscou um sentido de identidade que os alunos expressaram simbolicamente através dos gostos, objetos, valores e escolhas, que também expressam seu sentido relacional, pois, apesar de, geralmente, haverem discrepâncias entre o coletivo e o individual, fazendo com que as identidades não sejam unificadas, essas podem ser entendidas como unificadoras, já que agrupam indivíduos e lhes dão temporalidade e espacialidade.

Por fim, o trabalho teve como resultado uma maior conscientização dos alunos com os quais a atividade foi aplicada, que pôde ser observada ao longo do debate produzido em sala de aula e desenvolvido pelos próprios alunos, com poucas contribuições da bolsista. Assim, o ensino de geografia teve um papel importante no processo decolonial dos adolescentes que passaram a compreender melhor o processo histórico pelo qual o Brasil passou e como a miscigenação é fundamental na composição do povo brasileiro, que, apesar de agrupar as pessoas dentro de um núcleo coletivo, compreende as particularidades individuais de cada história. 


\section{Referências}

AGB. Nota Sobre a Reforma do Ensino Médio. Disponível em:

http://www.agb.org.br/index.php/57-nota-de-apoio/203-nota-sobre-a-reforma-do-ensinomedio Acesso em: 23 de abril de 2017

FREIRE, Paulo. Pedagogia da autonomia: saberes necessários à prática educativa. São Paulo: Paz e Terra, 1996. (coleção Leitura)

GUEDES, S. T. R.; SCHEUBAUER, A. R. Dá Prática do Ensino à Prática do Ensino: Os Sentidos da Prática na Formação dos Professores no Brasil no Século XX. Revista HISTEDBR On-line, Campinas, número especial, mai.2010, , p. 227-245. Disponível em: http://periodicos.sbu.unicamp.br/ojs/index.php/histedbr/article/viewFile/8639791/7354 Acesso em: 23 de abril de 2017

LÉVI-STRAUSS, C. "Raça e História". Disponível em: https://docs.google.com/viewer?a=v\&pid=sites\&srcid=ZGVmYXVsdGRvbWFpbnxhbnRjd Wx0aGlzdG9yaWF8Z3g6NTQ1MjJhMWZhNDEzOTFiZQ Acesso em: 13 de agosto de 2017

MELO, A. A.; VLACH, V. R. F.; SAMPAIO, A. C. F. História da Geografia Escolar Brasileira: Continuando a Discussão. Disponível em:

http://www2.faced.ufu.br/colubhe06/anais/arquivos/239AdrianyMelo_VaniaRubia.pdf Acesso em: 23 de abril de 2017

PORCHER, Louis. Educação Artística: Luxo ou Necessidade? São Paulo: Summus, 1982.

SECRETARIA DO ESTADO DO PARANÁ, Diretrizes Curriculares da Educação Básica Geografia. Disponível em:

http://www.educadores.diaadia.pr.gov.br/arquivos/File/diretrizes/dce_geo.pdf. Acesso em: 18 de abril de 2017.

VERSÃO ONLINE DO MANUAL DO PROFESSOR, Geografia. Coleção: Para Viver Juntos. Editora SM. Disponível em:

http://www.edicoessm.com.br/pnld2017_v1/assets/vj/GEOGRAFIA/7/conteudo/reader/. Acesso em: 18 de abril de 2017.

WOODWARD, Kathryn. Identidade e Diferença: Uma introdução. (In) SILVA, Tomaz Tadeu (org. e trad.). Identidade e diferença: a perspectiva dos estudos culturais. Petrópolis: Vozes, 2000. p. 73-102. 